\title{
Fractional flow reserve as the standard of reference: All that glistens is not gold
}

\author{
Dominik C. Benz, MD, a and Andreas A. Giannopoulos, MD, PhD a,b \\ a Cardiac Imaging, Department of Nuclear Medicine, University Hospital Zurich, Zurich, \\ Switzerland \\ b Cardiology Department, University Hospital Zurich, Zurich, Switzerland
}

Received May 18, 2019; accepted May 20, 2019

doi: $10.1007 / \mathrm{s} 12350-019-01771-3$

\section{See related article, pp. 1306-1313}

The burden of disease is directly linked to the prognosis of the patient-in cardiology as well as in any other field in medicine. The challenge, however, is whether and how the markers of clinical risk can guide patient management. ${ }^{1}$ While therapeutically targeting risk factors like LDL-cholesterol or blood pressure has substantially reduced major adverse cardiovascular events, ${ }^{2,3}$ this association has not yet been demonstrated for a risk marker like HDL-cholesterol. ${ }^{4}$ In contrast to statins or ACE-inhibitors that treat patients at risk holistically, the management of symptomatic patients with stable coronary artery disease (CAD) often demands vessel- or even lesion-specific therapies by coronary artery bypass grafting (CABG) or percutaneous coronary interventions (PCI). ${ }^{5}$ The value of anatomical and functional markers of disease burden in this setting, however, has been controversially debated over the last decades. Although the extent of CAD as defined by coronary artery calcium score or coronary CT angiography is a strong predictor of cardiovascular risk, ${ }^{6}$ the role of extensive or high-risk $\mathrm{CAD}$ in assigning patients to either myocardial revascularization or optimal medical treatment has so far been limited to observational data. ${ }^{7}$ Yet, comparing PCI to optimal medical treatment, one of the largest randomized trials to date demonstrated that anatomical disease burden-

Reprint requests: Andreas A. Giannopoulos, MD, PhD, Cardiac Imaging, Department of Nuclear Medicine, University Hospital Zurich, Ramistrasse 100, 8091 Zurich, Switzerland; Andreas.giannopoulos@usz.ch

J Nucl Cardiol 2020;27:1314-6.

1071-3581/\$34.00

Copyright (C) 2019 American Society of Nuclear Cardiology. although a marker of cardiovascular risk in the studydid not identify patients benefiting from PCI. ${ }^{8}$ As a result, the focus has shifted back to functional assessment of CAD as a marker of cardiovascular risk to potentially guide treatment strategy. ${ }^{9-11}$ Indeed, there is an indication from observational data that the burden of vessel-specific ischemia affects the response to revascularization. ${ }^{12}$ Whether the risk associated with higher ischemic burden can be reduced by revascularization is currently being prospectively investigated in the ISCHEMIA trial. ${ }^{13}$

Meanwhile, fractional flow reserve (FFR) in invasive coronary angiography has been validated against quantitative myocardial perfusion positron emission tomography (PET) imaging and non-invasive imaging 14,15 and emerged as a tool to assess lesion-specific ischemia. The severity of FFR has not only been linked to subsequent cardiovascular outcome ${ }^{16}$ but more importantly, an FFR-guided PCI strategy resulted in a significant reduction in urgent revascularizations. ${ }^{17}$ While FFR has since then been considered the gold standard for diagnostic accuracy studies as well as in clinical decision making, ${ }^{5}$ the technique appears to be underutilized in clinical routine ${ }^{18}$-due to a lack of experience, time, or reimbursement. Another reason might originate from the challenges in the interpretation of the FFR measurement: since the pathophysiological mechanisms leading to an abnormal FFR are still insufficiently understood, physicians might at times be confronted with striking discrepancies to findings from angiography or myocardial perfusion imaging. Consequently, reasonable doubts emerge.

In the current issue of the Journal of Nuclear Cardiology, Yokota et al. have addressed this issue of great clinical relevance in a prospective cohort study. ${ }^{19}$ In a sample of 133 patients with normal myocardial perfusion SPECT imaging, invasive coronary angiography with FFR measurement was performed due to 
persistent symptoms within 6 months after the SPECT scan. From the 85 FFR measurements that were performed in the LAD, 35\% were abnormal (FFR $\leq 0.8$ ). In contrast, only $10 \%$ of the 82 FFR measurements in non-LAD vessels were abnormal. Since only $30 \%$ of LAD measurements with abnormal FFR had angiographically obstructive CAD (compared to $75 \%$ of nonLAD measurements), the authors suggested that-in view of the normal SPECT findings-FFR might overestimate the severity of LAD lesions.

The authors should be commended for their effort to investigate this scientifically and clinically unsolved issue of discrepant FFR measurement. Although the authors' study design limits an analysis of the underlying mechanisms, their findings not only reflect the high prevalence but also elegantly highlight the clinical dilemma. Indeed, the reluctancy of revascularizing an angiographically non-obstructive lesion with a normal SPECT scan but an abnormal FFR is comprehensible to any physician-randomized data, nevertheless, would suggest an outcome benefit. Although the inaccuracy of angiography in assessing the functional relevance of obstructive $\mathrm{CAD}^{20}$ and the poor concordance of FFR with myocardial perfusion SPECT imaging is well established, ${ }^{21}$ the limitations of the axiomatic FFR are rarely called into question. While technical reasons might play a role in some cases, the discrepancies unfold hidden physiological interrelations too.

It has not been until recently that-beyond stenosis severity-atherosclerotic plaque characteristics such as positive remodeling or low attenuation plaque have been linked to abnormal FFR. ${ }^{22,23}$ Furthermore, the presence of abundant intracoronary and intercoronary collaterals impedes a direct comparison between lesion-specific ischemia from FFR and vessel-specific ischemia from myocardial perfusion SPECT imaging. ${ }^{24}$ Last but not least, applying Ohm's law to fluid flow, the pressuredrop (as measured by FFR) is directly related to (blood) flow. In patients with diffuse CAD or microvascular dysfunction where flow reserve is limited, there is less pressure-drop at a comparable lesion's resistance (or severity of stenosis). Conversely, non-obstructive CAD with low resistance could lead to an abnormal FFR if the flow is higher in healthier patients. Therefore, the results of the FAME 2 trial are not necessarily generalizable to all CAD patients. In view of the severity-benefit continuum for any risk factor, healthier patients might, therefore, only benefit from revascularization at a much lower threshold than the one suggested (e.g., 0.67 vs 0.80). ${ }^{16}$ Thanks to significant reduction in radiation exposure from coronary CT angiography, ${ }^{25-27}$ coronary lesions of younger and healthier patients are now being tested by CT-FFR or other CT-derived measurements. ${ }^{28-30}$ As a consequence, the interaction between lesion-specific ischemia and myocardial blood flow warrants further investigation to prevent overestimation of coronary lesions.

Since treating the risk factor $F F R$ by revascularization has improved cardiovascular outcomes in randomized trial, it is the most glittering tool that there is to guide treatment strategy. However, to correctly identify those patients that accrue prognostic benefit from revascularization, FFR should be assessed in the context of other risk markers like myocardial perfusion. Individualizing the threshold for an abnormal FFR by myocardial perfusion imaging or even quantification of myocardial blood flow could, therefore, result in an optimized-and potentially golden not only glitteringpatient management.

\section{Disclosure}

The University Hospital Zurich holds a research agreement with GE Healthcare. Dr. Benz reports a research grant from the Theodor und Ida Herzog-Egli-Foundation. Dr. Giannopoulos reports a research grant from the Iten-Kohaut-Foundation.

\section{References}

1. Stampfer MJ, Ridker PM, Dzau VJ. Risk factor criteria. Circulation 2004;109:IV3-5.

2. Silverman MG, Ference BA, Im K, Wiviott SD, Giugliano RP, Grundy SM, et al. Association between lowering LDL-C and cardiovascular risk reduction among different therapeutic interventions: A systematic review and meta-analysis. JAMA 2016;316:1289-97.

3. Touyz RM. Lower is better in hypertension, but how low should blood pressure be targeted? J Am Soc Hypertens 2016;10:621-2.

4. Mahdy Ali K, Wonnerth A, Huber K, Wojta J. Cardiovascular disease risk reduction by raising HDL cholesterol-current therapies and future opportunities. Br J Pharmacol 2012;167:1177-94.

5. Windecker S, Kolh P, Alfonso F, Collet JP, Cremer J, Falk V, et al. 2014 ESC/EACTS Guidelines on myocardial revascularization: The Task Force on Myocardial Revascularization of the European Society of Cardiology (ESC) and the European Association for Cardio-Thoracic Surgery (EACTS) Developed with the special contribution of the European Association of Percutaneous Cardiovascular Interventions (EAPCI). Eur Heart J 2014;35:2541619.

6. Clerc OF, Kaufmann BP, Possner M, Liga R, Vontobel J, Mikulicic F, et al. Long-term prognostic performance of low-dose coronary computed tomography angiography with prospective electrocardiogram triggering. Eur Radiol 2017;27:4650-60.

7. Min JK, Berman DS, Dunning A, Achenbach S, Al-Mallah M, Budoff MJ, et al. All-cause mortality benefit of coronary revascularization vs. medical therapy in patients without known coronary artery disease undergoing coronary computed tomographic angiography: results from CONFIRM (COronary CT Angiography EvaluatioN For Clinical Outcomes: An InteRnational Multicenter Registry). Eur Heart J 2012;33:3088-97. 
8. Mancini GB, Hartigan PM, Shaw LJ, Berman DS, Hayes SW, Bates ER, et al. Predicting outcome in the COURAGE trial (Clinical Outcomes Utilizing Revascularization and Aggressive Drug Evaluation): coronary anatomy versus ischemia. JACC Cardiovasc Interv 2014;7:195-201.

9. Benz DC, Gaemperli L, Gräni C, von Felten E, Giannopoulos AA, Messerli M, et al. Impact of cardiac hybrid imaging-guided patient management on clinical long-term outcome. Int $\mathrm{J}$ Cardiol 2018;261:218-22.

10. Pazhenkottil AP, Benz DC, Gräni C, Madsen MA, Mikulicic F, von Felten E, et al. Hybrid SPECT perfusion imaging and coronary CT angiography: Long-term prognostic value for cardiovascular outcomes. Radiology 2018;288:694-702.

11. Benz DC, Mikulicic F, Gräni C, Moret D, Possner M, Clerc OF, et al. Long-term outcome prediction by functional parameters derived from coronary computed tomography angiography. Int J Cardiol 2017;243:533-7.

12. Hachamovitch R, Hayes SW, Friedman JD, Cohen I, Berman DS. Comparison of the short-term survival benefit associated with revascularization compared with medical therapy in patients with no prior coronary artery disease undergoing stress myocardial perfusion single photon emission computed tomography. Circulation 2003;107:2900-7.

13. Hochman JS, Reynolds HR, Bangalore S, O'Brien SM, Alexander $\mathrm{KP}$, Senior R, et al. baseline characteristics and risk profiles of participants in the ISCHEMIA randomized clinical trial. JAMA Cardiol 2019;4:273-86.

14. De Bruyne B, Baudhuin T, Melin JA, Pijls NH, Sys SU, Bol A, et al. Coronary flow reserve calculated from pressure measurements in humans. Validation with positron emission tomography. Circulation 1994;89:1013-22.

15. Pijls NH, De Bruyne B, Peels K, Van Der Voort PH, Bonnier HJ, Bartunek JKJJ, et al. Measurement of fractional flow reserve to assess the functional severity of coronary-artery stenoses. N Engl J Med 1996;334:1703-8.

16. Johnson NP, Toth GG, Lai D, Zhu H, Acar G, Agostoni P, et al. Prognostic value of fractional flow reserve: linking physiologic severity to clinical outcomes. J Am Coll Cardiol 2014;64:1641-54.

17. De Bruyne B, Pijls NH, Kalesan B, Barbato E, Tonino PA, Piroth $\mathrm{Z}$, et al. Fractional flow reserve-guided PCI versus medical therapy in stable coronary disease. N Engl J Med 2012;367:991-1001.

18. Härle T, Zeymer U, Hochadel M, Zahn R, Kerber S, Zrenner B, et al. Real-world use of fractional flow reserve in Germany: Results of the prospective ALKK coronary angiography and PCI registry. Clin Res Cardiol 2017;106:140-50.

19. Yokota S, Borren NM, Ottervanger JP, Mouden M, Timmer JR, Knollema $\mathrm{S}$, et al. Does fractional flow reserve overestimate severity of LAD lesions? J Nucl Cardiol 2019. https://doi.org/10. 1007/s12350-019-01712-0.

20. Tonino PA, Fearon WF, De Bruyne B, Oldroyd KG, Leesar MA, Ver Lee PN, et al. Angiographic versus functional severity of coronary artery stenoses in the FAME study fractional flow reserve versus angiography in multivessel evaluation. J Am Coll Cardiol 2010;55:2816-21.

21. Melikian N, De Bondt P, Tonino P, De Winter O, Wyffels E, Bartunek J, et al. Fractional flow reserve and myocardial perfusion imaging in patients with angiographic multivessel coronary artery disease. JACC Cardiovasc Interv 2010;3:307-14.

22. Park HB, Heo R, Hartaigh B, Cho I, Gransar H, Nakazato R, et al. Atherosclerotic plaque characteristics by $\mathrm{CT}$ angiography identify coronary lesions that cause ischemia: a direct comparison to fractional flow reserve. JACC Cardiovasc Imaging 2015;8:1-10.

23. Giannopoulos AA, Benz DC, Gräni C, Buechel RR. Imaging the event-prone coronary artery plaque. J Nucl Cardiol 2019;26:14153.

24. van Lier MG, Oost E, Spaan JA, van Horssen P, van der Wal AC, vanBavel $\mathrm{E}$, et al. Transmural distribution and connectivity of coronary collaterals within the human heart. Cardiovasc Pathol 2016;25:405-12.

25. Benz DC, Gräni C, Hirt Moch B, Mikulicic F, Vontobel J, Fuchs TA, et al. Minimized radiation and contrast agent exposure for coronary computed tomography angiography: first clinical experience on a latest generation 256-slice scanner. Acad Radiol 2016;23:1008-14.

26. Benz DC, Fuchs TA, Gräni C, Studer Bruengger AA, Clerc OF, Mikulicic F, et al. Head-to-head comparison of adaptive statistical and model-based iterative reconstruction algorithms for submillisievert coronary CT angiography. Eur Heart J Cardiovasc Imaging 2018;19:193-8.

27. Benz DC, Templin C, Kaufmann PA, Buechel RR. Ultra-low-dose hybrid single photon emission computed tomography and coronary computed tomography angiography: A comprehensive and noninvasive diagnostic workup of suspected coronary artery disease. Eur Heart J 2015;36:3345.

28. Benz DC, Gräni C, Ferro P, Neumeier L, Messerli M, Possner M, et al. Corrected coronary opacification decrease from coronary computed tomography angiography: Validation with quantitative $13 \mathrm{~N}$-ammonia positron emission tomography. J Nucl Cardiol 2017. https://doi.org/10.1007/s12350-017-0980-2.

29. Douglas PS, Pontone G, Hlatky MA, Patel MR, Norgaard BL, Byrne RA, et al. Clinical outcomes of fractional flow reserve by computed tomographic angiography-guided diagnostic strategies vs. usual care in patients with suspected coronary artery disease: The prospective longitudinal trial of FFRCT: Outcome and resource impacts study. Eur Heart J 2015;36:3359-67.

30. Benz DC, Mikulicic F, Gräni C, Grossmann M, Giannopoulos AA, Messerli M, et al. Diagnostic accuracy of coronary opacification derived from coronary computed tomography angiography to detect ischemia: First validation versus single-photon emission computed tomography. EJNMMI Res 2017;7:92.

Publisher's Note Springer Nature remains neutral with regard to jurisdictional claims in published maps and institutional affiliations. 